\title{
Violência na escola: uma comparação entre duas escolas diferenciadas dentro de uma mesma comunidade.
}

\author{
Raquel Brum Fernandes ${ }^{1}$
}

Resumo: Já é grande a literatura internacional e nacional sobre a presença de violência dentro de instituições de ensino. É grande também a variedade de formas que a violência pode apresentar de acordo com a perspectiva a ser adotada pelo pesquisador: algumas são antigas, outras mais recentes e pertinentes às novas configurações urbanas, algumas operadas por membros da comunidade escolar, outras não. O caminho que minha pesquisa tem traçado para estudar como a violência acontece dentro da escola é através de como esse problema é vivenciado em expressões locais: tendo como objeto um CIEP e outra escola (não CIEP) de uma mesma localidade no município do Rio de Janeiro, busco evidenciar quais as diferenças e semelhanças na maneira como são experimentadas as ocorrências de violência dentro de cada uma das instituições. Para isso, tenho procurado compreender as percepções que os alunos têm das emoções que experimentam em relação a esses acontecimentos. Além disso busco evidenciar como as estruturas organizacionais das duas escolas se relacionam com essas vivências por parte dos estudantes.

Palavras-chave: Violência, escola, emoções, CIEP

\begin{abstract}
There is a great national and international literature on the presence of violence within educational institutions. There is also a great variety of forms under which violence can be presented according to the perspective being adopted by the researcher: some are old, others more recent and relevant to the new urban settings, some are operated by members of the school, others not. The path that my research has taken to study how violence happens inside schools is through how this problem is experienced in local expressions: working with a CIEP and another entirely different school (not CIEP) in the same locality of Rio de Janeiro as my objects, I seek to highlight what are the differences and similarities in the way that violence is experienced within each institution. Therefore I have sought to understand the perceptions that students have of their experienced emotions in relation to these events. In addition I seek to show how the organizational structures of the two schools are related to these experiences by the students.
\end{abstract}

Key words: Violence, school, emotions, CIEP

Résumé: C'est grande la littérature nationale et internationale sur la présence de violence au sein des établissements d'enseignement. Il y a aussi une grande variété de formes que la violence peut être présentée sous la perspective adopté par le chercheur: certaines sont anciennes, d'autres plus récentes et pertinentes pour les nouveaux paramètres urbains, d'autres exploitées par des membres de l'école, parfois non. Le chemin établi dans ma recherche pour étudier comment la violence se produit au coeur de l'école concerne la manière comment ce

\footnotetext{
${ }^{1}$ Raquel Brum Fernandes é doutoranda do Programa de Pós-Graduação em Ciências Sociais da Universidade do Estado do Rio de Janeiro (PPCIS/UERJ).
} 
problème est connu dans les expressions locales. Ayant comme objets un CIEP et une autre école (non CIEP) dans la même localité, au Rio de Janeiro, je cherche à mettre en évidence les différences et les similitudes dans la façon dont la violence est vécue au sein de chaque institution. Pour ce faire, j'ai cherché à comprendre les perceptions que les élèves aient sur les émotions qu'ils éprouvent par rapport à ces événements. En outre, je cherche à montrer comment les structures organisationnelles des deux écoles sont reliées à ces expériences par les étudiants.

Mots-clé: Violence, école, émotions, CIEP.

\section{Introdução}

Em 2007 trabalhei, em minha monografia de graduação, com a representação negativa a respeito dos Centros Integrados de Educação Pública (CIEPs), construídos durante o $1^{\circ}$ e o $2^{\circ}$ Programa Especial de Educação, nos governos Leonel Brizola no Rio de Janeiro. Reconhecia-se nesse projeto que os estudantes provenientes das camadas desprivilegiadas da sociedade necessitavam de uma escola que lhes proporcionasse as condições para o real aprendizado. Nas palavras de Darcy Ribeiro:

\footnotetext{
Traduzindo a proposta educacional do Governo do Estado ${ }^{2}$, o CIEP é fundamentalmente uma boa escola de $1^{\circ} \mathrm{Grau}$, funcionando em regime de dia completo, implantado pela primeira vez no Brasil. Cada CIEP, durante um período de oito horas diárias (inclusive horário de almoço), ministra aos alunos currículo do $1^{\circ}$ Grau, com aulas e sessões de Estudo Dirigido, além de oferecer atividades como esportes e participação em eventos culturais, numa ação integrada que objetiva elevar o rendimento global de cada aluno.

Tendo em vista as necessidades específicas da maioria dos alunos, provenientes dos segmentos sociais de baixa renda, o CIEP fornece assistência médico-odontológica, quatro refeições e banho todos os dias. (Ribeiro, 1986, p. 42)
}

Com o passar dos anos, os CIEPs foram perdendo algumas das atividades componentes de seu projeto inicial. Além disso, apesar de terem sofrido críticas desde sua origem, seu objetivo de beneficiar as classes populares e suas práticas de assistência

\footnotetext{
${ }^{2}$ Primeiro governo Brizola (1983-1986).
} 
aos alunos desenvolveram em determinados grupos sociais uma representação de que essas escolas eram depósitos de crianças marginalizadas, à qual foi acrescentado que o ensino era ruim, e a organização falha. Alguns estudos (CAVALIERI; COELHO, 2003) comprovam que, ao menos na rede estadual, os CIEPs realmente têm enfrentado períodos de instabilidade e perda de identidade. Entretanto, mesmo na Rede Municipal de Ensino do Rio de Janeiro, essas escolas têm progressivamente se distanciado de algumas de suas práticas iniciais. Por este motivo trabalhei com uma dessas instituições que apresentava características contrastantes com as idéias de senso comum: seus alunos obtinham altas notas no $\mathrm{IDEB}^{3}$, sua estrutura física era bem cuidada e sua organização eficaz, daí o título final de meu trabalho: Um CIEP que deu certo. Procurei analisar, então, o conjunto de fatores que fazia com que os alunos da referida escola conseguissem obter notas muito acima da média nacional ${ }^{4}$. Concluí que, naquele caso, algumas idéias do projeto inicial que ainda funcionavam na escola, como o horário integral e a realização de uma grande quantidade de atividades artísticas e esportivas, cooperavam para o aprendizado dos alunos, na medida em que se combinavam a outras práticas e circunstâncias favoráveis à eficácia da socialização escolar.

A partir dessa primeira pesquisa, segui trabalhando com CIEPs e a forma como se configuram atualmente, mais de 20 anos depois de sua implantação. Meu interesse nessa nova etapa era investigar uma nova relação: a das percepções das emoções em relação à violência que ocorre dentro do espaço escolar com as organizações e projetos educacionais das escolas escolhidas.

\section{Violência, educação e emoções}

Já é grande a literatura internacional e nacional sobre a presença de violência dentro de instituições de ensino. É grande também a variedade de formas que a violência pode apresentar de acordo com a perspectiva a ser adotada pelo pesquisador: algumas são antigas, outras mais recentes e pertinentes às novas configurações urbanas, algumas operadas por membros da comunidade escolar, outras não. A ocorrência de atos de violência dentro das escolas: "[...] contribui para rupturas com a idéia da escola

\footnotetext{
${ }^{3}$ Índice de Desenvolvimento da Educação Básica, calculado pelo Ministério da Educação com base nas notas de exames padronizados realizados por alunos de todo o país.

${ }^{4}$ A média dessa escola em 2005 que foi 5,5 era maior que a de toda rede pública nacional $(3,6)$, do estado $(3,7)$ e do município $(4,2)$.
} 
como lugar de conhecimento, de formação do ser e da educação, como veículo por excelência do exercício e aprendizagem, da ética e da comunicação por diálogo e, portanto, antítese da violência." (ABRAMOVAY , RUA, 2002, p.92). Um antagonismo se revela já que a escola, por ser compreendida como "lócus" de educação, teria como propósito formar indivíduos plenamente capazes de se relacionarem uns com os outros dentro dos padrões de comportamento legítimos.

A partir disso, o objetivo de minha pesquisa atual consiste em uma comparação: tendo como objeto um CIEP e outra escola (não CIEP) de uma mesma localidade no município do Rio de Janeiro, busco evidenciar quais as diferenças/semelhanças na maneira como são percebidas as ocorrências de violência, por parte dos alunos, dentro de cada uma das instituições. Focalizo assim a pesquisa por compreender que as ocorrências de violência não são outra coisa que as experiências que dela têm os diversos atores sociais envolvidos. Procurarei ainda evidenciar como as estruturas organizacionais das duas escolas se relacionam com essas vivências por parte dos estudantes. Para compreender essas experiências está sendo realizado o estudo das emoções suscitadas nos acontecimentos considerados violentos dentro da escola.

Maria Claudia Coelho (2006) afirmou que "o campo da antropologia das emoções conheceu, a partir de meados dos anos 80 nos Estados Unidos, um forte desenvolvimento" (pp.38). Ela destaca o trabalho de Michelle Rosaldo onde esta defende que, à partir especialmente do interpretativismo de C. Geertz, algumas noções, antes consideradas quase "naturais", foram reveladas como socialmente construídas. Entre essas noções estaria a de que os atores teriam uma individualidade interna não social e falando de Geertz a autora diz que ele "[...] insiste que significado é um fato público, que a vida pessoal toma forma em termos culturais, ou melhor ainda, talvez, que os indivíduos estão necessariamente e continuamente envolvidos na apreensão (ou transformação) interpretativa de modelos simbólicos recebidos.” (ROSALDO, 1984, pp.140, tradução minha). Dessa maneira, ao concebermos as emoções como socialmente construídas elas se tornam possível objeto de investigação para se compreender características da vida social de um determinado grupo.

Thomas Scheff é outro autor que defende "[...] a necessidade de incluir e estudar todas as partes da comunicação humana: gestos e emoções são tão importantes como palavras, pensamentos e ações.” (SCHEFF,1997, pp. 12). Ele acredita que a conduta humana é largamente explicada através dos vínculos sociais que desenvolvemos, sejam 
esses vínculos entre indivíduos e indivíduos, indivíduos e grupos e grupos e grupos (é certo que essas relações se misturam). A partir disso, o autor afirma que os atos de violência são gerados através de vínculos sociais inseguros, que produziriam uma alienação dos atores. Segundo ele, essa insegurança se apresentaria sob duas formas: ou os indivíduos estão envolvidos de maneira muito rígida onde ao menos um deles acaba se anulando em favor do outro ou do grupo, ou estão envolvidos de maneira muito dispersa, e ocorre uma intensa falta de compreensão e até rejeição mútua, gerando isolamento entre as partes. Os vínculos, então, para serem seguros deveriam apresentar um equilíbrio no que diz respeito às perspectivas dos diferentes atores envolvidos, revelando compreensão e identificação entre eles. É nesse sentido que se direciona meu trabalho.

No que diz respeito à metodologia, a definição do campo de pesquisa foi realizada com base em dados estatísticos disponibilizados no site do Instituto de Segurança Pública (ISP) ${ }^{5}$. Esse órgão realiza periodicamente um conjunto de análises a respeito dos atos criminosos ocorridos em todo o estado do Rio de Janeiro, com base nas ocorrências registradas em todas as regiões, divididas em 40 Áreas Integradas de Segurança Pública ${ }^{6}$. Realizei então uma comparação entre os dados criminalísticos de todas as "AISP”, procurando chegar à região que possuísse os maiores índices de delitos registrados durante o ano de 2008. Segundo o site, de todas as "AISP" do estado, a que apresentou um maior número de ocorrências acumuladas de janeiro a dezembro foi a área 09, localizada na capital estadual, abrangendo bairros que no sentido norte-sul vão desde a Pavuna até Quintino Bocaiúva, e no sentido leste-oeste de Vila Kosmos a Marechal Hermes.

Ainda que pretendesse questionar a variedade de fatores que podem influenciar a quantidade dos crimes que vem a ser registrados e, até em consequiência disso, a verossimilhança dos dados do ISP em relação a realidade criminal do estado, os números oficiais divulgados no site servem como direcionamento na procura por regiões onde a criminalidade é elevada. Desta maneira, a destacada posição da "AISP" 09 ( 48380 ocorrências sendo $24 \%$ de crimes contra a pessoa e 59,9\% de crimes contra

\footnotetext{
${ }^{5}$ O site define o ISP como uma "[...] autarquia criada em 1999, com o objetivo de colaborar na promoção dos saberes comuns à Segurança Pública, desenvolvendo projetos em parceria, pesquisas e análise criminal, além de um extenso conjunto de ações facilitadoras ao necessário diálogo entre as expressões da Segurança Estatal e a Sociedade Civil." < http://www.isp.rj.gov.br>

${ }^{6}$ Estas "AISP" foram divididas geograficamente de acordo com as áreas de atuação das Polícias Civil e Militar e cada uma delas corresponde a um dos 39 Batalhões dos Comandos de Policiamento de Área mais uma Unidade Operacional Especial, localizada em Campo Grande.
} 
o patrimônio) faz dessa área um provável lócus da violência mais explicita e reconhecida como tal.

Sabendo-se que a população local pode se relacionar com a constante presença de atos violentos de inúmeras formas, mais importante é saber que essas relações vão refletir e configurar os diversos contextos da vida social desses atores, inclusive a escola. Tanto que Alba Zaluar e Maria Cristina Leal (2001) falam da "rua" como um terceiro agente na socialização dos indivíduos, mesmo que em muitos casos aquela venha a defender valores e práticas antagônicas aos incentivados pela família e/ou pela escola (os dois primeiros agentes). Assim, o estudo de uma escola não pode ignorar os variados contextos socializadores aos quais seus atores estão expostos e nos quais a própria instituição está mergulhada, pois eles se mostram fundamentais para a compreensão do que se passa dentro dela. Sabemos que é ao município que é atribuída a responsabilidade pela oferta do Ensino Fundamental público e, portanto, a formação inicial dos indivíduos e que é na rede municipal também que se encontram os CIEPs que melhor tem conseguido preservar algumas características desde sua implantação (CAVALIERI; COELHO, 2003). Por isso, minha comparação foi feita entre um CIEP e uma escola pública convencional a fim de que a comparação em bases mais igualitárias fosse possível.

De acordo com a literatura da área, desde o processo de democratização do ensino, que se intensificou na década de 1970 (FARIA FILHO E VIDAL, 2000), as escolas públicas passaram a se configurar em sua maioria como típicas de alunos provenientes das camadas mais pobres ${ }^{7}$. Justamente nesses estratos sociais é que parecem ser sentidos, de maneira mais intensa, os efeitos da convivência com a violência. Alba Zaluar e Cristina Leal explicam que essa convivência aparece inclusive como um dos principais motivos para que meninos e meninas pobres saiam ou se tornem repetentes na escola. Dizem ainda que a escola pública não tem sido capaz de impedir a entrada de códigos de socialização contraditórios aos seus, e nem de lidar com esses novos códigos de maneira produtiva no que diz respeito à formação de um ambiente não violento (ZALUAR E LEAL, 2001). Dessa maneira, a escola pública se torna um local especialmente problemático no que diz respeito a seu relacionamento com a violência que a cerceia e penetra.

\footnotetext{
7 Salvas as exceções como os colégios de Aplicação de Universidades públicas, algumas instituições de ensino de grande tradição e etc.
} 
À partir de tudo isso, tendo escolhido a região e sabendo que seriam escolas públicas, cheguei a duas instituições não apenas no mesmo bairro, na AISP 09, mas também no mesmo CEP, para que as influências ao menos locais a que estivessem expostas fossem as mais semelhantes possíveis. Embora atualmente as variações no que diz respeito à organização ou projeto pedagógico entre os CIEPs e as escolas que não são desse tipo sejam cada vez menores, procurei por algum daqueles que ainda possuísse ao menos a característica identitária que me parece mais marcante: o horário integral. Isso para que, ao se manter explicita a diferenciação entre, ao menos, a organização das duas instituições, fosse possível uma comparação entre as formas com que as duas se relacionam com as experiências de violência que seus atores sociais tem dentro delas.

\section{Notas sobre observação participante}

Ao iniciar a observação participante, minha entrada nas escolas divergiu na maneira como as professoras me introduziram entre os alunos. No CIEP, a professora de uma das turmas com que tenho trabalhado me apresentou como alguém que estaria ali para observá-los em um sentido de vigiá-los, chegando a dizer alguns dias depois que eu anotaria o nome daqueles alunos que se comportassem mal e passaria as anotações para a coordenadora. Levei alguns dias para provar aos alunos que não era essa minha intenção e que não falaria nada do que visse ou ouvisse nem para a professora, nem para ninguém da direção da escola. Compreendi, nesse momento, o quanto minha posição de observadora em uma escola de Ensino Fundamental poderia se revelar ambígua para os atores sociais daquele universo. Tendo chegado às escolas portando uma autorização para pesquisa da Secretaria Municipal de Educação (S.M.E.), autorização esta que pouco falava sobre mim, que me dava livre acesso ao cotidiano escolar por um largo tempo e ainda cuja única restrição era que respeitasse os horários escolares, fiquei livre para explicar ou não explicar o que julgasse necessário. Ao mesmo tempo, ficava claro que eu era alguém não subordinada à direção da escola e por isso digna de desconfiança.

À partir disso, e também pela aparência e idade, compreendo a dificuldade dos grupos envolvidos de elaborar minha presença na sala de aula. Ao falar para os alunos que eu estava ali para vigiá-los, a professora enfatizava minha condição de adulta, e portanto, senão especificamente professora (o que não era porque ela explicou aos 
alunos no primeiro dia que eu não tinha autoridade de liberá-los para sair da sala e coisas afins), ao menos tendenciosa a concordar e cooperar com ela. Essa tentativa se mostrou mais explícita também pelo fato de insistirem em dizer dentro da escola que eu era uma estagiária, mesmo eu tendo explicado a todos que fazia mestrado em Ciências Sociais e que aquele universo era o objeto de minha pesquisa de dissertação. Inicialmente, achei que se tratava apenas de uma falta de compreensão do meu trabalho e até achei positivo, porque havia estagiárias de pedagogia em ambas as escolas e então imaginei que assumindo essa posição mesmo que passivamente, estaria obtendo quase que um "disfarce" que me possibilitaria dar menos explicações e passar mais despercebida. Entretanto, ao longo da observação, esse papel mostrou complicações. Em um dos primeiros dias, essa mesma professora que havia me apresentado como quase uma vigia, falou, em tom de brincadeira, com a professora da outra turma com a qual estou trabalhando, que iria reclamar com a S.M.E porque tinham mandado para ela uma estagiária que não podia fazer nada, que era só para observar. Senti-me impelida a ajudar em alguma coisa. Pensei em me oferecer para realizar alguma tarefa, o que confirmaria minha condição fictícia de estagiária. Entretanto, o fato de minha pesquisa concentrar-se nas percepções por parte dos alunos, limitou minha preocupação de integrar-me com as professoras, fez com que passasse a ressaltar que não era estagiária e a agir o mínimo "professora-friendly"8 que conseguisse.

Adotei então, desde os primeiros dias, uma postura explicitamente direcionada à integração com os alunos, ou à tentativa de que eles desconstruíssem a idéia de eu ser "tia" (estagiária ou não) e todas as noções relativas à essa posição. Dessa forma, até hoje, nunca realizei nenhuma tarefa que fosse explicitamente de "tia", pelo contrário, já fiz junto com os alunos algumas atividades peculiares deste grupo: um dia escrevi junto com eles toda a tabuada de dois a dez, seis vezes cada. Na outra escola participei de uma competição de pular elástico. Obviamente, também não contei para a professora sobre o que ouvia, e ainda me fiz de despercebida ao ver circulando dentro de sala de aula doces e biscoitos, o que não é permitido. É claro que por mais que brinque com eles ou me recuse a almoçar com as professoras, nada disso é capaz de retirar os quase 15 anos de idade que me separam dos alunos e que fazem de mim uma tia quase que indiscutível. Mas achei necessário, principalmente após as tentativas claras das professoras de me enquadrar em um grupo que elas já conhecem e cujas ações são

\footnotetext{
${ }^{8}$ No sentido de favorável às professoras.
} 
delimitadas (o das estagiárias), procurar ao máximo desenvolver um relacionamento de confiança com as crianças, onde minhas reações às ações deles não fossem tão circunscritas à uma posição de autoridade, ou de educadora, da minha parte.

Essa tendência de rapidamente colocar a pesquisadora em uma posição conhecida, a de estagiária (quase uma igual) por parte das professoras e de "tia" (uma adulta na sala de aula) por parte dos alunos, nos leva ao segundo ponto que desejo discutir aqui: ao tentar me enquadrar e principalmente, ao me ver tentando fugir da noção de estagiária, percebi em algumas professoras uma preocupação com aquilo que eu poderia reprovar e escrever (divulgar) sobre o trabalho delas. É claro que essa preocupação de ser avaliado pelo pesquisador não é exclusiva no meu universo de pesquisa. Mas, ao se tratar de violência em uma área altamente marginalizada que são as escolas públicas principalmente dentro de favelas, essa preocupação parece tomar ares mais explícitos. Teresa Caldeira (2000) e Néstor Perlongher (1987) já chamaram atenção para casos onde desejamos saber sobre assuntos cujos atores envolvidos podem querer não falar explicitamente, podem negar e podem inclusive julgar inapropriado que alguém, na posição de pesquisador, obtenha maiores informações. Embora não tenha dito para nenhum aluno ou professora o tema explícito de meu trabalho, nem que estava relacionado à violência, pude perceber claramente que a concepção que tinham de mim, já os fazia demonstrar certa vergonha, ao falar ou realizar na minha frente atos que consideravam violentos. É certo que, com o passar do tempo, os alunos, principalmente, foram tendo cada vez menos restrições, na medida em que viam que eu não os repreendia (embora também tente que não pareça que os estou apoiando) em determinadas ações. Norbert Elias diz que:

A vergonha tira sua coloração específica do fato de que a pessoa que a sente fez ou está prestes a fazer alguma coisa que a faz entrar em choque com pessoas a quem está ligada de uma forma ou de outra, e consigo mesma, com o setor de sua consciência mediante o qual controla a si mesma. O conflito expressado no par vergonha-medo não é apenas um choque do indivíduo com a opinião social prevalecente: seu próprio comportamento colocou-o em conflito com a parte de si mesmo que representa essa opinião. (ELIAS, 1994, pp.242) 
Nesse sentido, percebi que, minha condição de "tia" suavizada, fez com que as professoras demonstrassem mais vergonha daquilo que imaginam que eu, enquanto representante da opinião social (que elas imaginam qual seja por também terem dentro delas, segundo Elias, essa opinião) não vá aprovar. Já com os alunos a relação é inversa, pois na medida em que vou estabelecendo um relacionamento menos hierárquico com eles, diminui a necessidade de sentirem "vergonha", ou de sentirem que posso reproválos. Novamente nas palavras de Elias:

O sentimento de vergonha é uma exaltação específica, uma espécie de ansiedade que automaticamente se reproduz na pessoa em certas ocasiões, por força do hábito. Considerado superficialmente, é um medo de degradação social ou, em termos mais gerais, de gestos de superioridade de outras pessoas. (ELIAS, 1994, p.242)

Como se tratam de alunos de quinto ano (a partir de 10 anos) já são amplamente socializados até na escola para imaginarem aquilo que é ou não reprovado pelo grupo de professoras, diretoras e etc. Como quero saber a percepção que os alunos têm daquilo que eles consideram violência, iniciei a observação participante sem ter definido quais acontecimentos seriam ou não considerados relevantes para mim, ou seja, quais seriam ou não considerados violentos. A idéia era que os próprios alunos, ao comentar os acontecimentos, demonstrassem aquilo que consideravam importante ou não. Dessa maneira, fez-se amplamente necessária essa tentativa de diminuição na hierarquia entre eu e eles. Acredito que atualmente, após os devidos ajustes, temos conseguido um relacionamento favorável à evolução da minha pesquisa.

\section{REFERÊNCIAS BIBLIOGRÁFICAS}

ABRAMOVAY, Miriam; RUA, Ma. Das Graças. Violência nas escolas. Brasília: UNESCO,2001.

BOMENY, H. COELHO, M.C. SENTO-SÉ, J.T. Violência nas Escolas Públicas do Rio de Janeiro: notas exploratórias sobre a autoridade docente e as percepções da violência. 
CALDEIRA, T. A fala do crime. In.: Cidade de muros. Crime, segregação e cidadania em São Paulo. Editora 34/Edusp, 2000.

CAVALIERE, Ana Maria e COELHO, Lígia Martha. Para onde caminham os cieps : uma análise após 15 anos. Cadernos de Pesquisa, São Paulo, 2003. n. 119, p. 147-174.

COELHO, M. C. P. Emoção, Gênero e Violência: experiências e relatos de vitimização. In: Vi Reunião de Antropologia do Mercosul, 2005, Montevidéu. VI Reunión de Antropología del Mercosur - Identidad, Fragmentación y Diversidad, 2005

ELIAS, Norbert. O processo civilizador. Rio de Janeiro: Jorge Zahar Ed., vol 2, 1994.

FERNANDES, R. Um CIEP que deu certo. Rio de Janeiro: 2008.

PERLONGHER, N. O Negócio do michê. Prostituição viril em São Paulo. 1987. Brasiliense

RIBEIRO, Darcy. O livro dos CIEPS. Rio de Janeiro, Bloch, 1986

ROSALDO, Michelle. (1984). "Toward an Anthropology of Self and Feeling", in R. Shweder e R. LeVine (orgs.) - Culture Theory - Essays on Mind, Self, and Emotion Cambridge, Cambridge University Press.

SCHEFF, T.J. Emotions, the social bond and human reality: part/whole analysis, Cambridge University Press, 1997. 